\title{
Atherosclerotic Cardiovascular Disease Short-Term Risk Estimate among Civilian Licensed Aircrew
}

\author{
Nathan B. Buila1,2, Jean-Marc B. Bantu ${ }^{3}$, Gilbert K. Kabanda', Pascal M. Bayauli ${ }^{4}$, \\ Aliocha N. Nkodila ${ }^{5}$, François B. Lepira ${ }^{6}$, Symphorien M. Ditu ${ }^{4}$, Jean-René M'Buyamba-Kabangu ${ }^{*}$ \\ ${ }^{1}$ Division of Cardiology and Hypertension, Kinshasa School of Medicine, University of Kinshasa, Kinshasa, DR Congo \\ ${ }^{2}$ Civil Aviation Authority, Kinshasa, DR Congo \\ ${ }^{3}$ Departments of Cardiology, Chirec Clinics, Brussels, Belgium \\ ${ }^{4}$ Division of Endocrinology and Metabolic Diseases, Kinshasa School of Medicine, University of Kinshasa, Kinshasa, DR Congo \\ ${ }^{5}$ Centre Médical Cité des Aveugles, Kinshasa, DR Congo \\ ${ }^{6}$ Division of Nephrology, Kinshasa School of Medicine, University of Kinshasa, Kinshasa, DR Congo \\ Email: ^jerembu@yahoo.fr
}

How to cite this paper: Buila, N.B., Bantu, J.-M.B., Kabanda, G.K., Bayauli, P.M., Nkodila, A.N., Lepira, F.B., Ditu, S.M. and M'Buyamba-Kabangu, J.-R. (2019) Atherosclerotic Cardiovascular Disease Short-Term Risk Estimate among Civilian Licensed Aircrew. World Journal of Cardiovascular Diseases, 9, 92-108.

https://doi.org/10.4236/wjcd.2019.92010

Received: December 24, 2018

Accepted: February 17, 2019

Published: February 20, 2019

Copyright (C) 2019 by author(s) and Scientific Research Publishing Inc. This work is licensed under the Creative Commons Attribution International License (CC BY 4.0).

http://creativecommons.org/licenses/by/4.0/

\begin{abstract}
Background: Flight and cabin crew are known to be at increased risk for atherosclerotic cardiovascular disease (ASCVD). However, ASCVD risks have not yet been compared in flight and cabin crew in low resource settings like sub-Saharan Africa. Objectives: To assess absolute ASCVD risk estimate and its clinical correlates among flight and cabin crew. Methods: From June $1^{\text {st }}$ 2015 to December $30^{\text {th }} 2015,379$ consecutive aviation navigants (Flight crew: $62.5 \%$, pilots: $46.2 \%$, women: $29.6 \%$, Caucasians $23.2 \%$ ) were enrolled in a cross-sectional survey of ASCVD risk estimate using the Framingham tools. They underwent a physical examination for either initial or renewal medical certificate Class 1 or 2 including blood chemistry, ECG, and echocardiogram as per International Civil Aviation Organization (ICAO) and Civil Aviation Authority (CAA-DRC) medical regulations. We modeled the risk of moderate and high ASCVD estimate in a stepwise logistic regression. Results: Low, moderate and high ASCVD risk estimates were observed respectively in 248 (65.4\%), 64 (16.9\%), and 67 (17.7\%) navigants. Moderate and high ASCVD risk estimates predominated among flight than cabin crew (23.6\% vs. $5.6 \%$; $p$ $<0.0001$ and $28.3 \%$ vs. null; $\mathrm{p}<0.001$ ), low ASCVD risk estimate among cabin than flight crew ( $94.4 \%$ vs. $48.1 \%$; $\mathrm{p} \leq 0.001)$. Low ASCVD risk estimates were mostly encountered in Blacks (86.5\%) and moderate in Caucasians (43.8\%). Clinical correlates of moderate ASCVD risk estimates included being flight crew (adjusted OR 3.33 [1.42 - 7.81]; $\mathrm{p}=0.006$ ), Caucasian (adjusted OR 2.71 [1.43 - 5.15]; $\mathrm{p}=0.002$ ), and having proteinuria (adjusted OR
\end{abstract}


5.78 [2.38 - 14-01]; $\mathrm{p}<0.001)$. For high ASCVD risk estimate, the main associated factors were total flight time $\geq 5000 \mathrm{~h}(3.71$ [3.67 - 5.17]; $\mathrm{p}<0.001)$, overweight/obesity (adjusted OR 2.10 [1.48 - 9.20]; p = 0.033), high resting HR (adjusted OR 2.85 [1.51 - 5.98]; p = 0.023), LVH (adjusted OR 4.50 [1.13 7.94]; $\mathrm{p}=0.032$ ) and high serum uric acid (adjusted OR 3.66 [1.49 - 5.61]; $\mathrm{p}=$ 0.041). Conclusion: In the present case series, moderate and high ASCVD risk estimates were present in 3 out of 10 navigants and racial, traditional risk factors and flight crew status were the main correlates of these ASCVD risk estimates.

\section{Keywords}

Cardiovascular Risk, Aircrew, Frequency, Clinical Correlates

\section{Introduction}

Atherosclerotic Cardiovascular Diseases (ASCVDs) are associated with an increased risk of disability and premature mortality especially in developing countries such as those of Sub-Saharan Africa (SSA) [1]. Therefore, prevention, screening and early management of ASCVDs have been recommended as a rationale strategy to alleviate the burden of ASCVDs on individuals, families and communities [1]. The implementation and success of such a strategy require the identification of groups at risk for CVD and associated risk factors. Likewise, the Work Group's Approach to Risk Assessment strongly argues for sustained research related to short-and long term ASCVD risk in various groups [2]. Due to less physical activity associated with their professional life, the aircrew could be considered as a group at high ASCVD risk. To this regard, ASCVDs are the leading etiology of loss of license, disqualifying a person to carry out aeronautical duties [3]. In addition, ASCVDs linked to unexpected in-flight medical incapacitation or impairment account for half of human factor-related causes of aviation accidents [4]. Moreover, 10 of the 98 in-flight medical events addressed by the Australian Transport Safety Bureau between 1 January 1975 and 31 March 2006, consisted of heart attack explaining the high-observed mortality rate [5]. Thus, International Civil Aviation Organization (ICAO) recommends to country members to use routinely homogeneous cardiovascular likelihood management recommendations and ASCVD likelihood estimate scores in aeromedical risk assessment to help alleviating morbidity and mortality in aeronautical setting (area).

In the Democratic Republic of the Congo (DRC), screening for aircrew is performed by Aero-Medical Examiners (AMEs) working with Aeronautical Medical Centers (AMCs) accredited by the Civilian Aviation Authority (CAA)-DRC. We took advantage of the activities of these centers to carry out the present survey to assess ASCVD risk estimate in aircrew (flight vs. cabin crew). We hypothesized that ASCVD risk estimate in flight crew is higher than that in cabin crew. 


\section{Methods}

From June $1^{\text {st }} 2015$ to December $30^{\text {th }} 2015$, licensed aircrew attending Congolese AMCS' appointed by the CCA-DRC for their initial or renewal of aeromedical license were consecutively enrolled in a cross-sectional survey of ASCVD risk assessment. According to ICAO and CAA/DRC regulations, aircrew was categorized as Flight (Pilots and flight engineers) and cabin crew. For each navigant, trained medical team using ad hoc questionnaire collected socio-demographic data (age, gender, total flight time, aircrew license held), medical background (kin, history of hypertension and diabetes) and information on lifestyle (alcohol and tobacco intake, and physical activity) after an oral informed consent had been obtained.

A succinct physical examination including anthropometric (height, weight, waist circumference, hip circumference) and BP measurements was performed. Weight and height were measured using a FAZZINI scale (Italy), and a tape measurer, respectively, the subject lightly clothed and barefooted. Waist circumference (WC) was measured at the least respiration to the nearest centimeter at the partway of the inferior rib margin and the anterior superior iliac crest, in the standing position. The body mass index (BMI) was calculated as weight in kilogram $(\mathrm{Kg})$ divided by the square of height in meters $\left(\mathrm{m}^{2}\right)$. Overweight and obesity were defined as BMI between $25.0 \mathrm{~kg} \cdot \mathrm{m}^{-2}$ and $30 \mathrm{~kg} \cdot \mathrm{m}^{-2}$ or more than 30 $\mathrm{kg} \cdot \mathrm{m}^{-2}$, respectively [6]. Abdominal obesity was defined in the Africans as WC > $94 \mathrm{~cm}$ in men and $>80 \mathrm{~cm}$ in women and in Caucasians as WC $>102 \mathrm{~cm}$ in men and $>88 \mathrm{~cm}$ in women [7]. According to 2018 European Society of Hypertension (ESH) and European Society of Cardiology (ESC) guidelines, seated BP was measured after 5 minutes rest on the left arm using an automatic certified device (OMRON M6, HEM 7001) [8]. Three readings 3 minutes apart were made and the average of the three readings was considered for data analysis. Hypertension was defined as BP of at least $140 \mathrm{mmHg}$ systolic and/or $90 \mathrm{mmHg}$ diastolic, and/or use of high blood pressure lowering drugs [8].

A 12-hour fasting venous blood sample was obtained for each participant for the measurement of glucose, total cholesterol (TC), high-density lipoprotein cholesterol (HDL-c), triglycerides (TG), blood urea nitrogen (BUN), creatinine, and uric acid. Low-density lipoprotein cholesterol (LDL-c) was calculated using the Friedewald formula [9]. Dyslipidemia was defined as TC $>200 \mathrm{mg} \cdot \mathrm{dL}^{-1}$, $\mathrm{LDL}-\mathrm{c} \geq 100 \mathrm{mg} \cdot \mathrm{dL}^{-1}$, and/or HDL-c $<50 \mathrm{mg} \cdot \mathrm{dL}^{-1}$ (women) or $40 \mathrm{mg} \cdot \mathrm{dL}^{-1}$ (men). Type-2 diabetes mellitus (T2DM) was a fasting blood glucose $>126 \mathrm{mg} \cdot \mathrm{dL}^{-1}$, and/or a self-reported diagnosis, and/or the use of hyperglycemic lowering medications; impaired glucose intolerance was fasting blood glucose between 100 and $126 \mathrm{mg} \cdot \mathrm{dL}^{-1}$ [10]. According to International Diabetes Federation (IDF), metabolic syndrome (MetS) was defined as the presence of abdominal adiposity associated with at least two of the following characteristics: $\mathrm{BP}>130 / 85 \mathrm{mmHg}$ and/or use of high blood pressure lowering drugs, fasting blood glucose $>100$ $\mathrm{mg} \cdot \mathrm{dL}^{-1}$ and/or diagnosed T2DM, serum triglycerides $>150 \mathrm{mg} \cdot \mathrm{dL}^{-1}$ or use of 
lipid lowering drugs, $\mathrm{HDL}$ cholesterol $<50 \mathrm{mg} \cdot \mathrm{dL}^{-1}$ in women or $<40 \mathrm{mg} \cdot \mathrm{dL}^{-1}$ in men [11]. Semi quantitative proteinuria was assessed using dipstick test (Medi Test Combi 9, Düren, Germany) and dipstick 1+ defined positive proteinuria.

A resting 12-lead electrocardiogram (ECG) was performed to measure heart rate. An echocardiography (GE Logic 5) with M-mode, 2D, pulsed, and color-flow doppler functions was used to measure the left atrium diameter, aortic diameter, left ventricle (LV) internal diameter at end diastole (LVIDd) and at end of systole (LVIDs), the posterior wall thickness at end diastole (PWTd) and at end systole (PWTs), and the septum thickness at end diastole (STd) and at end systole (STs). We applied appropriate formulas [12] to compute LV mass indexed (LVMI), LV hypertrophy (LVH), systolic and diastolic ventricular dysfunctions.

A short (10-year) ASCVD risk estimate was generated and vascular heart age was calculated using recommended Framingham Heart Study chart, a risk prediction model assigning weight (points) to traditional risk factors for ASCVD such as age, total cholesterol (mg/dL), HDL-cholesterol (mg/dL), treated or untreated SBP (yes or no), smoking status (yes or no), and T2DM (yes or no) [13]. Likewise, the mentioned variables have not been accounted in our multivariate stepwise model. ASCVD risk estimate was considered as low $(\leq 6 \%)$, moderate (between $6 \%$ and $9 \%$ ), or high ( $\geq 10 \%)$ [14]. Heart age/vascular has been classified as less than 40 years, between 40 and 49 years, between 50 and 59 years, and 60 years or higher.

\section{Statistical Methods}

Data were presented as frequencies or mean \pm standard deviation as applicable. The Student's t-test was used to compare means and the Pearson's Chi-squared or Fisher's exact test as appropriate for proportions. The adjusted odd ratio values and $95 \%$ of confidence interval were determined. We modeled the risk of moderate and high ASCVD estimate in a stepwise logistic regression. Analyzes were performed using the Statistical Package for Social Sciences version 17.0 (SPSS Inc., Chicago, IL), and the significance level was set at $\mathrm{p}<0.05$.

\section{Results}

The aircrew-studied population comprised of 379 individuals average age 40 years, (extremes 19 and 70 years) with Caucasians, females, and flight crew representing $23.2 \%, 29.6 \%$, and $62.5 \%$ of the sample, respectively. Clinical and biological baseline characteristics according to their ASCVD risk estimate categories (low, moderate, and high) by the Framingham risk score are depicted in Table 1 and in Table 2.

Overall, ASCVD risk estimate was low in 248 (65.4\%), whilst 64 (16.9\%) and 67 (17.7\%) had moderate or high ASCVD risk estimate, respectively. High ASCVD risk estimate included $61.2 \%$ Blacks, $88.6 \%$ pilots with 5000 hours or more. But neither female nor cabin crew had high ASCVD risk estimate; $\mathrm{p}<0.001$ (Table 1). 
Table 1. Baseline characteristics of the aircrew according to their ASCVD risk estimate categories.

\begin{tabular}{|c|c|c|c|c|}
\hline \multirow{3}{*}{ Characteristic } & \multicolumn{4}{|c|}{ ASCVD risk estimate } \\
\hline & Low & Moderate & High & \multirow{2}{*}{$\mathbf{P}$} \\
\hline & $(\mathrm{n}=248,65.4 \%)$ & $(\mathrm{n}=64,16.9 \%)$ & $(\mathrm{n}=67,17.7 \%)$ & \\
\hline Age, mean (SD) & $33.5(8.3)$ & $49.8(7.9)$ & $58.1(6.0)$ & $<0.001$ \\
\hline Age, n (\%) & & & & $<0.001$ \\
\hline$<40 y$ & $193(77.8)$ & $6(9.4)$ & $0(0.0)$ & \\
\hline $40-59 y$ & $54(21.8)$ & $52(81.3)$ & $34(50.7)$ & \\
\hline$\geq 60 y$ & $1(0.4)$ & $6(9.4)$ & $33(49.3)$ & \\
\hline Sex, n (\%) & & & & $<0.001$ \\
\hline Man & $139(56.0)$ & $61(95.3)$ & $67(100.0)$ & \\
\hline Women & $109(44.0)$ & $3(4.7)$ & $0(0.0)$ & \\
\hline Race, n (\%) & & & & $<0.001$ \\
\hline Black & $214(86.3)$ & $36(56.3)$ & $41(61.2)$ & \\
\hline White or other & $34(13.7)$ & $28(43.8)$ & $26(38.8)$ & \\
\hline Aircrew category, n (\%) & & & & $<0.001$ \\
\hline Flight crew & $114(46.0)$ & $56(87.5)$ & $67(100.0)$ & \\
\hline Cabin crew & $134(54.0)$ & $8(12.5)$ & $0(0.0)$ & \\
\hline Total flight time, hours & $4153.3(4130.7)$ & $8553.7(5847.9)$ & $13343.3(6112.8)$ & $<0.001$ \\
\hline Total flight time, hours & & & & $<0.001$ \\
\hline$<5000$ & $61(69.3)$ & $15(34.9)$ & $5(11.4)$ & \\
\hline$\geq 5000$ & $27(30.7)$ & $28(65.1)$ & $39(88.6)$ & \\
\hline Tobacco, cigarettes & $5.6(4.2)$ & $6.3(2.3)$ & $6.8(4.1)$ & 0.401 \\
\hline Alcohol, mean (SD), gram & $23.7(13.6)$ & $21.8(9.7)$ & $25.3(13.2)$ & $<0.001$ \\
\hline Systolic blood pressure, $\mathrm{mmHg}$ & $114.9(14.0)$ & $129.2(12.8)$ & $139.4(20.1)$ & $<0.001$ \\
\hline Diastolic blood pressure, $\mathrm{mmHg}$ & $73.3(8.8)$ & $83.4(9.5)$ & $86.4(11.2)$ & $<0.001$ \\
\hline Mean blood pressure, $\mathrm{mmHg}$ & $86.3(9.7)$ & $98.1(10.70$ & $103.6(13.4)$ & $<0.001$ \\
\hline Pulse pressure, $\mathrm{mmHg}$ & $41.7(10.7)$ & $45.9(9.7)$ & $53.0(13.8)$ & 0.705 \\
\hline Body mass index, $\mathrm{kg} / \mathrm{m}^{2}$ & $25.5(4.3)$ & $28.2(3.9)$ & $28.7(4.3)$ & $<0.001$ \\
\hline Waist-to-hip ratio & $0.87(0.06)$ & $0.92(0.06)$ & $0.93(0.06)$ & $<0.001$ \\
\hline Heart rate, bpm & $68.7(10.5)$ & $68.8(15.1)$ & $73.7(17.4)$ & 0.017 \\
\hline Fasting blood glucose, $\mathrm{mg} / \mathrm{dL}$ & $85.3(16.9)$ & $88.2(22.4)$ & $86.9(23.0)$ & 0.515 \\
\hline Total cholesterol, mg/dL & $170.5(37.7)$ & $183.2(51.6)$ & $166.6(52.9)$ & 0.06 \\
\hline Serum uric acid, mg/dL & $6.1(1.8)$ & $6.2(1.8)$ & $6.6(1.9)$ & 0.26 \\
\hline Lipids, mg/dL & $512.9(151.5)$ & $535.1(176.9)$ & $514.8(173.8)$ & 0.707 \\
\hline $\begin{array}{l}\text { high-density } \\
\text { lipoprotein-cholesterol, mg/dL }\end{array}$ & $65.6(22.8)$ & $59.4(22.0)$ & $54.1(17.6)$ & $<0.001$ \\
\hline $\begin{array}{l}\text { low-density } \\
\text { lipoprotein-cholesterol, mg/dL }\end{array}$ & $83.6(49.0)$ & $94.7(48.5)$ & $90.4(42.9)$ & 0.198 \\
\hline
\end{tabular}




\section{Continued}

\begin{tabular}{lcccc}
\hline Triglycerides, mg/dL & $98.7(73.5)$ & $127.6(99.7)$ & $86.4(47.0)$ & 0.005 \\
$\begin{array}{l}\text { Creatinine, mg/dL } \\
\text { Blood Urea Nitrogen, mg/dL }\end{array}$ & $1.03(0.25)$ & $1.02(0.24)$ & $1.05(0.24)$ & 0.765 \\
$\begin{array}{l}\text { Estimated glomerular filtration } \\
\text { rate, } \mathrm{mL} / \mathrm{min} / 1.73 \mathrm{~m}^{2}\end{array}$ & $99.8(26.7)$ & $93.4(22.8)$ & $87.4(20.2)$ & 0.001 \\
\hline
\end{tabular}

Data are expressed as mean (standard deviation), absolute frequency (n), and relative frequency (in percent). Abbreviations: ASCVD: Atherosclerotic cardiovascular disease.

Table 2. CVD risk factors in licensed aircrew according to their ASCVD risk estimate.

\begin{tabular}{ccccc}
\hline & \multicolumn{3}{c}{ ASCVD risk estimate } \\
\cline { 2 - 4 } Characteristics & Low & Moderate & High & p \\
\cline { 2 - 4 } & $\mathbf{n}=\mathbf{2 4 8}$ & $\mathbf{n}=64$ & $\mathbf{n}=67$ & \\
\hline Tobacco use & $36(14.5)$ & $15(23.4)$ & $29(43.3)$ & $<0.001$ \\
Alcohol use & $162(65.3)$ & $48(75.0)$ & $49(73.1)$ & 0.204 \\
Physical inactivity & $199(80.2)$ & $62(96.9)$ & $67(100.0)$ & $<0.001$ \\
Hypertension & $27(10.9)$ & $27(42.2)$ & $43(64.2)$ & $<0.001$ \\
Abdominal obesity & $133(53.6)$ & $43(67.2)$ & $48(71.6)$ & 0.01 \\
Overweight & $81(32.7)$ & $28(45.3)$ & $32(47.8)$ & $<0.001$ \\
Obesity & $43(17.3)$ & $22(34.4)$ & $26(38.8)$ & $<0.001$ \\
Types-2 diabetes mellitus & $2(0.8)$ & $3(4.7)$ & $6(9.0)$ & 0.001 \\
Impaired glucose tolerance & $45(18.1)$ & $11(17.2)$ & $8(11.9)$ & 0.487 \\
High serum uric acid & $27(13.4)$ & $9(17.6)$ & $14(29.8)$ & 0.03 \\
Dyslipidemia & $137(55.2)$ & $41(64.1)$ & $47(70.1)$ & 0.06 \\
Diastolic dysfunction & $25(10.1)$ & $6(9.4)$ & $8(11.9)$ & 0.879 \\
Metabolic syndrome & $26(10.5)$ & $15(23.4)$ & $22(32.8)$ & $<0.001$ \\
Renal failure & $14(5.6)$ & $5(7.8)$ & $4(6.0)$ & 0.734 \\
Proteinuria & $15(6.0)$ & $12(18.8)$ & $2(3.0)$ & 0.002 \\
\hline
\end{tabular}

Data are expressed as absolute frequency (n), and relative frequency (in percent). Abbreviations: ASCVD: Atherosclerotic cardiovascular disease.

Among flight crew, $48.1 \%, 23.6 \%$ and $28.3 \%$ had respectively a low, moderate and high ASCVD risk estimate. This differs $(\mathrm{p}<0.001)$ from the results among cabin crew in whom a larger proportion $(94.4 \%)$ had low risk, whilst respectively $5.6 \%$, and $0.0 \%$ had moderate or high ASCVD risk estimate (Figure 1).

ASCVD risk estimate was associated with aging and total flight time. Globally, aircrew members with low ASCVD risk were younger than those with moderate or high risk (Table 1). Indeed, low ASCVD risk estimate predominated among subjects less than 40 years (77.8\%), moderate risk estimate among those aged 40 - 59 years (81.3\%), and high ASCVD risk estimate among those aged 60 and older (49.3\%). Similarly, in pilots ASCVD risk estimate linearly increased $(\mathrm{p}<$ 

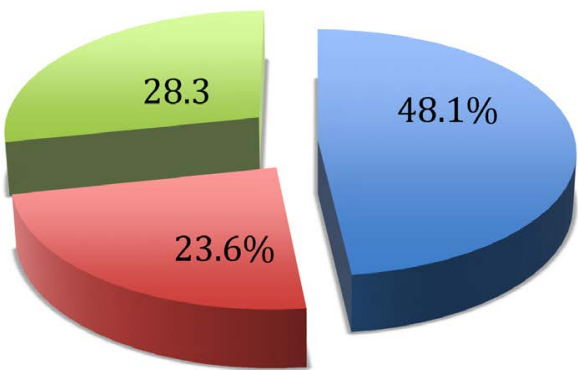

(a)

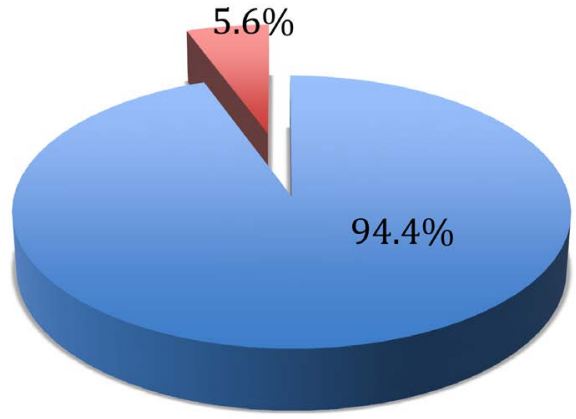

(b)
Low ASCVD

Moderate ASCVD

High ASCVD

\section{- Low ASCVD}

Moderate ASCVD

High ASCVD

Figure 1. Prevalence of low, moderate, and high ASCVD risk estimate in flight $(\mathrm{n}=237)$ (a) and cabin crew $(\mathrm{n}=142)(\mathrm{b})$.

0.001) with the flight time from low (69.3\%) in those with less than 5000 hours to high (88.6\%) among those with 5000 hours more (Table 1).

Globally, the majority of Blacks were at low ASCVD risk estimate whilst Caucasians were at moderate ASCVD risk estimate, $\mathrm{p}<0.001$. The respective prevalence of low, moderate and high ASCVD risk estimate in Black vs Caucasian aircrew amounted to $86.3 \%$ vs $13.7 \%, 56.3 \%$ vs $43.8 \%$, and $61.2 \%$ vs $38.8 \%$ (Table 1).

The value of SBP, DBP, MBP, BMI, WHR, and heart rate were greater in subjects with high ASCVD risk estimate compared to those with low and moderate ASCVD risk estimate whilst eGFR and HDL-c showed an inverse trend. On the other hand pulse pressure, uric acid, lipid, LDL-c, creatinine, and BUN were similar in all categories of ASCVD risk estimate, $p \geq 0.116$ (Table 2).

The rate of tobacco use, hypertension, T2DM, overall and abdominal adiposity; and moreover, physical inactivity, high serum uric acid and metabolic syndrome increased with the categories of ASCVD risks, $\mathrm{p} \leq 0.03$ or less (Table 2).

ECG and echocardiographic profiles are depicted in Table 3 according to ASCVD risk estimate categories. In comparison to aircrew with low and moderate ASCVD risk estimate, those with high ASCVD risk estimate had faster resting heart rate, greater QTc, aortic diameter, LAD, LVIDd, STd, PWTd, and LVMI, $\mathrm{p} \leq 0.001$. Thus the rate of LVH increased with the categories of ASCVD risk estimate. Concentric pattern of LVH was present in 2.8\%, 3.6\%, and 31.7\% for aircrew with low, moderate, and high ASCVD risk estimate, respectively; these proportions were $1.4 \%, 3.6 \%$, and none for eccentric pattern. Contrarily, 
Table 3. ECG and echographic profiles of licensed aircrew according to ASCVD risk estimate.

\begin{tabular}{|c|c|c|c|c|}
\hline \multirow{3}{*}{ Characteristic } & \multicolumn{3}{|c|}{ Atherosclerotic Cardiovascular Risk } & \multirow{3}{*}{$\mathrm{p}$} \\
\hline & Low & Moderate & High & \\
\hline & $(\mathrm{n}=248)$ & $(\mathrm{n}=64)$ & $(\mathrm{n}=67)$ & \\
\hline \multicolumn{5}{|l|}{ ECG profiles } \\
\hline Resting heart rate, mean (SD), bpm & $68.71(10.5)$ & $68.78(15.09)$ & $73.69(17.43)$ & 0.017 \\
\hline QTc, ms & $380.88(31.55)$ & $387.16(37.23)$ & $395.95(33.35)$ & 0.003 \\
\hline High resting heart rate, $\mathrm{n}(\%)$ & $11(4.4)$ & $4(6.3)$ & $8(11.9)$ & 0.002 \\
\hline \multicolumn{5}{|l|}{ Echocardiographic profiles } \\
\hline Aortic diameter, $\mathrm{mm}$ & $29.5(3.8)$ & $32.0(4.3)$ & $32.7(4.4)$ & $<0.001$ \\
\hline $\mathrm{LAD}, \mathrm{mm}$ & $30.6(4.2)$ & $32.5(4.1)$ & $34.0(4.8)$ & $<0.001$ \\
\hline LViDd, mm & $45.8(4.7)$ & $48.8(4.9)$ & $49.7(4.7)$ & $<0.001$ \\
\hline LViDs, mm & $22.9(3.2)$ & $24.4(4.1)$ & $24.7(4.4)$ & $<0.001$ \\
\hline $\mathrm{STd}, \mathrm{mm}$ & $8.7(1.3)$ & $9.4(1.4)$ & $10.6(2.4)$ & $<0.001$ \\
\hline STs, mm & $16.1(1.8)$ & $16.8(1.6)$ & $17.6(2.3)$ & $<0.001$ \\
\hline PWTd, mm & $8.7(1.3)$ & $9.3(1.5)$ & $10.5(2.3)$ & $<0.001$ \\
\hline PWTs, mean (SD), mm & $15.5(1.4)$ & $15.9(1.6)$ & $16.9(2.3)$ & $<0.001$ \\
\hline LVMI, $\mathrm{mg} / \mathrm{m}^{2}$ & $70.5(19.9)$ & $80.5(21.5)$ & $98.0(35.9)$ & $<0.001$ \\
\hline cLVEF, \% & $78.5(4.4)$ & $78.6(4.9)$ & $78.6(6.2)$ & 0.975 \\
\hline Peak E-velocity, m/s & $0.65(0.07)$ & $0.67(0.09)$ & $0.66(0.09)$ & 0.27 \\
\hline Peak A-velocity, m/s & $0.58(0.07)$ & $0.59(0.07)$ & $0.59(0.9)$ & 0.278 \\
\hline E/A ratio & $1.13(0.13)$ & $1.14(0.16)$ & $1.12(0.14)$ & 0.958 \\
\hline DcT, ms & $177.8(15.7)$ & $175.9(16.2)$ & $178.4(16.6)$ & 0.616 \\
\hline Diastolic dysfunction, $\%$ & $25(10.1)$ & $6(9.4)$ & $8(11.9)$ & 0.879 \\
\hline LVH, \% & $6(2.4)$ & $3(4.7)$ & $15(22.4)$ & $<0.001$ \\
\hline LV geometry & & & & $<0.001$ \\
\hline Normal geometry, n (\%) & $178(82)$ & $42(75)$ & $37(61.7)$ & \\
\hline Concentric remodeling, $\mathrm{n}(\%)$ & $30(13.8)$ & $10(17.9)$ & $4(6.7)$ & \\
\hline Concentric hypertrophy, n (\%) & $6(2.8)$ & $2(3.6)$ & $19(31.7)$ & \\
\hline Eccentric hypertrophy, n (\%) & $3(1.4)$ & $2(3.6)$ & $0(0)$ & \\
\hline
\end{tabular}

Data are expressed as mean (standard deviation), absolute frequency (n), and relative frequency (in percent). Abbreviations: ASCVD: Atherosclerotic cardiovascular disease, ECG: electrocardiogram, LV: left ventricle, LVIDd: LV internal diameter at end diastole, LVIDs: LV internal diameter at the end of systole, LAD: left atrium diameter, PWTd: posterior wall thickness at end diastole, PWTs: posterior wall thickness at end systole, LVMI: LV mass indexed, LVH: LV hypertrophy, STd: septum thickness at end diastole, STs: septum thickness at end systole, cLVEF: Corrected LV ejection fraction, E: early diastolic mitral inflow velocity, A: late diastolic mitral inflow velocity, DcT: Deceleration time.

LVEF corrected, peak E-velocity, peak A-velocity, E/A ratio, and DcT were similar in the categories of the ASCVD risks, $\mathrm{p}=0.975$ or higher (Table 3 ).

Overall, the average aircrew vascular age was older than the chronological 
one. Moreover, the average vascular age of flight crew (56.85 $\pm 16.6 \mathrm{y})$, pilots at $\geq 5000$ flight hours $(64.1 \pm 13.6 \mathrm{y})$, males $(55.8 \pm 16.6)$, Caucasians $(59.9 \pm 16.0 \mathrm{y})$ was higher when compared to their counterparts (Figure 2).

Table 4 depicts independent factors associated with moderate and high ASCVD risk estimate. In multivariate modeling, the odds to present moderate ASCVD risk estimate were higher for Caucasians (odd ratio: 2.71 [95\% confidence interval: $1.43-5.15] ; \mathrm{p}=0.002)$, flight crew (3.33 [1.42 - 7.81]; $\mathrm{p}=0.006)$, and proteinuria (5.78 [2.38 - 14-01]; $\mathrm{p}<0.001)$.

For high ASCVD risk estimate, factors independently associated were total flight time $\geq 5000$ hours (3.71 [3.67 - 5.17]; $\mathrm{p}<0.001)$, overweight/obesity $(2.10$ $[1.48-9.20] ; \mathrm{p}=0.033)$, fast resting heart rate $(2.85[1.51-5.98] ; \mathrm{p}=0.023), \mathrm{LVH}$ $(4.50[1.13-7.94] ; \mathrm{p}=0.032)$, and high uric acid (3.66 [1.49-5.61]; $\mathrm{p}=0.041)$.

Table 4. Independent determinants of moderate and high ASCVD risk estimate in multiple stepwise regression analysis.

\begin{tabular}{|c|c|c|c|c|}
\hline \multirow[t]{2}{*}{ Characteristic } & \multicolumn{2}{|c|}{ Moderate ASCVD risk estimate } & \multicolumn{2}{|c|}{ High ASCVD risk estimate } \\
\hline & $\mathrm{P}$ & OR (C.I.95\%) & $\mathrm{P}$ & ORa (C.I.) 95\%) \\
\hline Caucasians vs. African flight crew & 0.002 & $2.71(1.43-5.15)$ & 0.346 & $1.57(0.62-3.99)$ \\
\hline $\begin{array}{l}\text { Total flight time, hours, } \geq 5000 \text { vs. } \\
<5000\end{array}$ & & & $<0.001$ & $3.71(3.67-5.17)$ \\
\hline Flight crew vs. Cabin crew & 0.006 & $3.33(1.42-7.81)$ & & \\
\hline $\begin{array}{c}\text { Death before } 50 \mathrm{y} \text { in close relative, } \\
\text { no vs. yes }\end{array}$ & & & 0.585 & $1.52(0.34-6.87)$ \\
\hline Subclinic atherosclerosis, no vs. yes & & & 0.736 & $1.26(0.34-4.69)$ \\
\hline Overweight/obesity, no vs. yes & 0.304 & $1.46(0.71-3.01)$ & 0.033 & $2.10(1.48-9.20)$ \\
\hline High resting heart rate, no vs. yes & & & 0.023 & $2.85(1.51-5.98)$ \\
\hline $\begin{array}{l}\text { Left ventricular hypertrophy (yes } \\
\text { vs. no) }\end{array}$ & & & 0.032 & $4.50(1.13-7.94)$ \\
\hline High serum uric acid, no vs. yes & & & 0.041 & $3.66(1.49-5.61)$ \\
\hline Proteinuria, no vs. yes & $<0.001$ & $5.78(2.38-14.01)$ & & \\
\hline
\end{tabular}

Abbreviations: ASCVD: Atherosclerotic cardiovascular disease; ORaj: adjusted Odd ratio; CI: confidence interval.

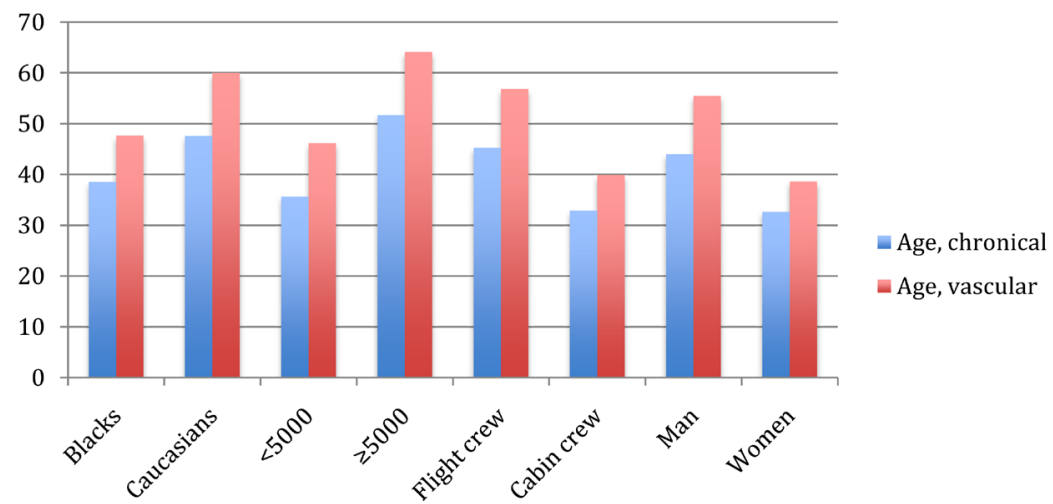

Figure 2. Averaged vascular vs. chronological age in aircrew according to their race, fight time, profession, and gender. 


\section{Discussion}

The salient findings of this cross-sectional survey are as follows: Firstly, flight crew has higher ASCVD risk estimate compared with cabin crew; secondly, ASCVD risk estimate linearly increased with aircrew' age; thirdly, Caucasians and flight crew status, and proteinuria are independent predictors of moderate ASCVD risk estimate; and finally, total flight time $\geq 5000$ hours, overweight/obesity, faster resting heart rate, $\mathrm{LVH}$, and high serum uric acid are independent predictors of high ASCVD risk estimate. This study offers important contributions not only in understanding the ASCVD impact of flight duties in aircrew, but also in allowing individuals at intermediate and high ASCVD risk estimates to be treated.

In our study, nearly 2 out of 5 pilots had high ASCVD risk estimate. Moreover, due to their higher prevalence of cardiovascular risk factors the proportion of flight crew with high ASCVD risk estimate was greater than that of cabin crew. In a retrospective cross-sectional study among Colombian civilian aviation pilots a $20.2 \%$ prevalence of high estimate risk of ASCVDs was documented using the Framingham multivariate tools [15]. The authors considered their results were probably biased, as the Framingham tools used were neither calibrated nor validated for local population, and this consideration might be pertaining to our African settings.

The ASCVD risk estimate increases, as the aircrew gets older. That age is totally a non-modifiable risk factor is arguable as the impact of age on ASCVD is not homogeneous since it depends on the burden of other coexisting traditional ASCVD risk factors [16] [17]. Instead of displaying a cliché, ageing could express the magnitude and the time span of exposure to other traditional ASCVD risk factors [18]. Ageing has been listed to be associated with physiological alterations such as mitochondrial [19] and endothelial [20] dysfunction; angiogenesis impairment [21], telomere attrition [22], and abnormal growth factor synthesis [23], as well as FOXOs/Sirtuins [24] implications. These mechanisms lead to not only the heart but also the vasculature alterations involving hypertrophy, LV diastolic and endothelial dysfunction and arterial stiffness [25].

Being Caucasians, having $\geq 5000$ total flight hours, and proteinuria emerged as independent predictors of moderate ASCVD risk estimate. Our study pointed out that living in Africa appeared to enhance prediction for moderate ASCVD risks in Caucasians compared with African aircrew. By contrast to our findings, reports from sundry epidemiologic studies documented higher hypertension prevalence and BP levels, lower BP control and greater risks from hypertension in African-American compared with white, with higher salt sensitivity and body mass index, resistant and refractory hypertension accounting for those variances [26] [27]. Similar variances have been reported between British and West African and Caribbean individuals [28]. Possible pathophysiological pathways might explain these disparities as we found that Caucasians had higher SBP, DBP, BMI, WHR, and LVMI compared with African aircrew. Moreover, the proportion of 
tobacco use was higher in Caucasians compared with African aircrew. Lloyd-Jones et al. recently reported that smoking was associated significantly with high ASCVD risk and reduced 5 years survival regardless of gender [29]. Contrastingly, nonsmokers had longer life lived and delayed the onset of CVDs [30].

Pilots with $\geq 5000$ flight hours had moderate ASCVD risk estimate. Guohua Li et al. posited that total flight time expresses significantly the likelihood of crash involvement compared with aging, which encompasses a conflict between decreasing cognitive functions that jeopardizes flight safety increase and improved flying expertise that enhances safety. Furthermore, these authors found that having 5000 hours or more of total flight time protects against crash involvement but this protection levels off at a threshold of 10,000 flight hours [31]. Likewise, $\mathrm{Li}$ and Baker addressed an inverse nonlinear relationship between crash involvement and total flight time [32].

Evidence now posits proteinuria to be a predictive risk factor for ASCVD morbidity and mortality [33]. Indeed, proteinuria is associated with hypertension [34], ischemic heart disease [34], T2DM [35], heart failure, and surrogate cardiovascular risk makers (carotid artery intima media thickness [36] [37], LVH [38], elevated coronary artery calcium scores [39], and carotid-femoral pulse wave velocity [40]). The underlying mechanism includes not only inflammation but also endothelial dysfunction and altered thrombogenesis [41].

High ASCVD risk estimate increases with faster resting heart rate in our survey. The explanation could lie in its relationship with hypertension, the cornerstone of the Framingham ASCVD risk estimation. Similarly, fast resting heart rate has been found to be associated with CVD outcomes although reducing heart rate, for instance by using ibavradine, an If inhibitor, on the purpose to improve outcomes has yielded controversial results [42].

We found that echo-based LVH was an independent predictor of high ASCVD risk estimate. Earlier deemed as a remodeling mechanism to counteract the strained pressure on the heart, echo-based LVH is now reckoned to be an independent predictor of cardiovascular risk, and a key element in scoring overall risk and in offering therapy guidance [43] [44]. When it comes to allude to ECG-based LVH, one should be advised that whilst one- or all-criteria-ECG-based LVH is associated with ASCVD risks, it does help neither to reclassify nor to predict ASCVD risks over the Framingham tools, which are laid on traditional factors for cardiovascular risks [45].

Our results highlight that high serum acid uric was independently associated with high ASCVD risk estimate. Similarly, several clinical and epidemiological surveys using multivariate modeling techniques suggested that high serum uric acid was an independent risk factor for cardiorenal diseases [46]. One has argued that high serum uric acid in mother predisposes a child to develop high blood pressure throw nephropenia due to low birth weight [47]. Moreover, the uric acid physiopathological pathways had been studied utilizing animal models and cellular culture [48]. In fact, both the decreasing of the excretion and the in- 
creasing of the generation of uric acid summarized the elevation of UA in individuals with cardiorenal disease. The former is met in conditions such as altered glomerular filtration rate, hyperinsulinemia, renal vasoconstriction, or diuretic medication use, whilst the latter in alcohol use, tissue ischemia, or oxidative stress [49]. By contrast the Framingham Heart Study group [50] and other [51] stated that high serum uric acid was not per se an independent cardiovascular risk CVD unless when clustering with other cardiovascular risk factors.

Our data indicate the aircrew vascular age was older compared with the chronological age even in various racial (Caucasians vs. African), flight time ( $<5000 \mathrm{~h}$ vs. $\geq 5000 \mathrm{~h}$ ), gender (male vs. female), or professional (flight vs. cabin crew) categories. In fact, vascular age is of essence for quantifying and comprehending risk, and indicates the variance of life-years-lost [52]. Framingham heart study investigators stressed the likelihood for an individual with normal CVD risk factors to have high CVD risk estimate [53].

Because ASCVD often appears in individuals with lower CVD risk estimate, some other markers such as high-sensitivity C-reactive protein (hs-CRP), coronary artery calcium score (CAC), cardiorespiratory fitness, apolipoprotein B (ApoB), micro-albuminuria, carotid intima-media thickness (CIMT), and ankle-brachial index (ABI) need to be evaluated [54]. Whilst these novel biomarkers may be considered to inform treatment decision making, they could not help a CV risk-based treatment decision [55]. Furthermore, using new variables such as genetic markers may enhance CV prediction even if this possibility remains questionable [56].

Our study has several limitations. Firstly we transported the Framingham tools in non-totally Framingham settings. Secondly, since our study was enclosed one professional category, its results may not be generalized to other settings. Finally, factors associated with moderate to higher ASCVD risk may not be strong for the cross-sectional nature of our survey.

\section{Conclusion}

The most important findings in the current study were the huge variances in ASCVD risk estimate between flight and cabin crew. Also beyond traditional risk factors used in the Framingham tools, whilst being Caucasians or flight crew has been associated with moderate ASCVD, total flight time $\geq 5000$ hours, overweight/obesity, faster resting heart rate, $\mathrm{LVH}$, and high serum uric acid have been associated with high ASCVD risk estimate. Therefore, these results stress the need for dissemination, implementation, and even, revision of ASCVD risk estimate in Congolese daily AME practices. New ASCVD risk lowering strategies should be taken in Caucasians aircrew living in Africa and randomized control trials designed to assess those variances.

\section{Acknowledgements}

The authors gratefully thank both the Civil Aviation Authority/DRC and the 
AMC-African Union Presidential Medical Center along with their administration for data assistance.

\section{Author's Contribution}

NBB designed the study, participated in data analysis and wrote the manuscript. BJM interpreted data and reviewed the manuscript. GKK participated in data collection and reviewed the manuscript. PBM reviewed the manuscript. ANN interpreted data and conducted data analysis. LFB contributed to the study design and reviewed the manuscript. JRKM, the guarantor, contributed to the study design and reviewed the manuscript.

\section{Conflicts of Interest}

The authors declare no conflicts of interest regarding the publication of this paper.

\section{References}

[1] Roth, G.A., Johnson, C., Abajobir, A., Abd-Allah, F., Abera, S.F., Abyu, G. and Murray, C. (2017) Global, Regional, and National Burden of Cardiovascular Diseases for 10 Causes, 1990 to 2015. Journal of the American College of Cardiology, 70, 1-25. https://doi.org/10.1016/j.jacc.2017.04.052

[2] 2013 ACC/AHA Guideline on the Assessment of Cardiovascular Risk. A Report of the American College of Cardiology/American Heart Association Task Force on Practice Guidelines.

[3] Ekstrand, K., Boström, P.-A., Arborelius, M., Nilsson, J.-Å. and Lindell, S.-E. (1996) Cardiovascular Risk Factors in Commercial Flight Aircrew Officers Compared with Those in the General Population. Angiology, 47, 1089-1094. https://doi.org/10.1177/000331979604701109

[4] DeJohn, C.A., Wolbrink, A.M. and Larcher, J.G. (2006) In-Flight Medical Incapacitation and Impairment of Airline Pilots. Aviation, Space, and Environmental Medicine, 77, 1077-1079.

[5] Newman, D.G. (2006) Pilot Incapacitation: Analysis of Medical Conditions Affecting Pilots Involved in Accidents and Incidents 1 January 1975 to 31 March 2006. ATSB Transport Safety Report, Aviation Research and Analysis Report, B2006/0170.

[6] Finucane, M.M., Stevens, G.A., Cowan, M., et al. (2011) National, Regional, and Global Trends in Body Mass Index Since 1980: Systematic Analysis of Health Examination Surveys and Epidemiological Studies with 960 Country-Years and 9.1 Million Participants. Lancet (London, England), 377, 557-567. https://doi.org/10.1016/S0140-6736(10)62037-5

[7] Pischon, T., Boeing, H., Hoffmann, K., Bergmann, M., Schulze, M.B., et al. (2008) General and Abdominal Adiposity and Risk of Death in Europe. New England Journal of Medicine, 359, 2105-2120. https://doi.org/10.1056/NEJMoa0801891

[8] (2018) 2013 ESH/ESC Guidelines for the Management of Arterial Hypertension: The Task Force for the Management of Arterial Hypertension of the European Society of Cardiology (ESC), and of the European Society of Hypertension (ESH). European Heart Journal, 1-98.

[9] Friedelwald, W.T., Levy, R.I. and Fredrickson, D.S. (1972) Estimation of the Con- 
centration of Low-Density Lipoprotein Cholesterol in Plasma without Use of the Preparative Ultracentrifuge. Clinical Chemistry, 18, 499-502.

[10] ADA American Diabetes Association (2010) Diagnosis and Classification of Diabetes Mellitus. Diabetes Care, 33, S62. https://doi.org/10.2337/dc10-S062

[11] Alberti, K.G.M.M., Eckel, R.H., Grundy, S.M., Zimmet, P.Z., Cleeman, J.I., Donato, K.A., Fruchart, J.C., James, W.P.T., Loria, C.M. and Smith Jr., S.C. (2009) Harmonizing the Metabolic Syndrome: A Joint Interim Statement of the International Diabetes Federation Task Force on Epidemiology and Prevention; National Heart, Lung, and Blood Institute; American Heart Association; World Heart Federation; International Atherosclerosis Society; and International Association for the Study of Obesity. Circulation, 120, 1640-1645. https://doi.org/10.1161/CIRCULATIONAHA.109.192644

[12] Lang, R.M., Badano, L. and Afilalo, J. (2015) Chamber Quantification Writing Group, American Society of Echocardiography's Guidelines, Standards Committee, European Association of Echocardiography. Recommendations for cardiac chamber quantification by echocardiography: an update from the American Society of Echocardiography and the European Association of Cardiovascular Imaging. Journal of the American Society of Echocardiography, 28, 1-39. https://doi.org/10.1016/j.echo.2014.10.003

[13] D’Agostino Sr, R.B., Vasan, R.S., Pencina, M.J., Wolf, P.A., Cobain, M., Massaro, J.M. and Kannel, W.B. (2008) General Cardiovascular Risk Profile for Use in Primary Care: The Framingham Heart Study. Circulation, 117, 743-753. https://doi.org/10.1161/CIRCULATIONAHA.107.699579

[14] Hoang, K., Ghandehari, H. and Lopez, V.A. (2008) Global Coronary Heart Disease Risk Assessment of US Persons with the Metabolic Syndrome. Diabetes Care, 31, 1405-1409. https://doi.org/10.2337/dc07-2087

[15] Arteaga-Arredondo, L.F. and Fajardo-Rodríguez, H.A. (2010) Cardiovascular Risk Factor Prevalence in Civil Aviation Pilots in Colombia during 2005. Revista de Salud Publica (Bogota), 12, 250-256. https://doi.org/10.1590/S0124-00642010000200008

[16] Sniderman, A.D. and Furberg, C.D. (2008) Age as a Modifiable Risk Factor for Cardiovascular Disease. The Lancet, 371, 1547-1549. https://doi.org/10.1016/S0140-6736(08)60313-X

[17] Obas, V. and Vasan, R.S. (2018) The Aging Heart. Clinical Science, 132, 1367-1382. https://doi.org/10.1042/CS20171156

[18] Dhingra, R. and Vasan, R.S. (2012) Age as a Risk Factor. Medical Clinics of North America, 96, 87-91. https://doi.org/10.1016/j.mcna.2011.11.003

[19] Dutta, D., Calvani, R., Bernabei, R., Leeuwenburgh, C. and Marzetti, E. (2012) Contribution of Impaired Mitochondrial Autophagy to Cardiac Aging: Mechanisms and Therapeutic Opportunities. Circulation Research, 110, 1125-1138. https://doi.org/10.1161/CIRCRESAHA.111.246108

[20] Seals, D.R., Jablonski, K.L. and Donato, A.J. (2011) Aging and Vascular Endothelial Function in Humans. Clinical Science, 120, 357-375. https://doi.org/10.1042/CS20100476

[21] Paneni, F., Diaz Canestro, C., Libby, P., Luscher, T.F. and Camici, G.G. (2017) The Aging Cardiovascular System: Understanding It at the Cellular and Clinical Levels. Journal of the American College of Cardiology, 69, 1952-1967. https://doi.org/10.1016/j.jacc.2017.01.064

[22] Fyhrquist, F. and Saijonmaa, O. (2012) Telomere Length and Cardiovascular Aging. 
Annals of Medicine, 44, S138-S142. https://doi.org/10.3109/07853890.2012.660497

[23] Fontana, L., Vinciguerra, M. and Longo, V.D. (2012) Growth Factors, Nutrient Signaling, and Cardiovascular Aging. Circulation Research, 110, 1139-1150. https://doi.org/10.1161/CIRCRESAHA.111.246470

[24] Oellerich, M.F. and Potente, M. (2012) FOXOs and Sirtuins in Vascular Growth, Maintenance, and Aging. Circulation Research, 110, 1238-1251. https://doi.org/10.1161/CIRCRESAHA.111.246488

[25] Lakatta, E.G. and Levy, D. (2003) Arterial and Cardiac Aging: Major Shareholders in Cardiovascular Disease Enterprises, Part I: Aging Arteries: A “Set Up" for Vascular Disease. Circulation, 107, 139-146. https://doi.org/10.1161/01.CIR.0000048892.83521.58

[26] Lakatta, E.G. and Levy, D. (2003) Arterial and Cardiac Aging: Major Shareholders in Cardiovascular Disease Enterprises, Part II: The Aging Heart in Health: Links to Heart Disease. Circulation, 107, 346-354. https://doi.org/10.1161/01.CIR.0000048893.62841.F7

[27] Profant, J. and Dimsdale, J.E. (1999) Race and Diurnal Blood Pressure Patterns. A Review and Meta-Analysis. Hypertension, 33, 1099-1104. https://doi.org/10.1161/01.HYP.33.5.1099

[28] Lane, D., Beevers, D.G. and Lip, G.Y. (2002) Ethnic Differences in Blood Pressure and the Prevalence of Hypertension in England. Journal of Human Hypertension, 16, 267-273. https://doi.org/10.1038/sj.jhh.1001371

[29] Lloyd-Jones, D.M., Leip, E.P., Larson, M.G., et al. (2006) Prediction of Lifetime Risk for Cardiovascular Disease by Risk Factor Burden at 50 Years of Age. Circulation, 113, 791-798. https://doi.org/10.1161/CIRCULATIONAHA.105.548206

[30] Mamun, A.A., Peeters, A., Barendregt, J., Willekens, F., Nusselder, W. and Bonneux, L. (2004) Smoking Decreases the Duration of Life Lived with and without Cardiovascular Disease: A Life Course Analysis of the Framingham Heart Study. European Heart Journal, 25, 409-415. https://doi.org/10.1016/j.ehj.2003.12.015

[31] Li, G., Baker, S.P., Grabowski, J.G., Qiang, Y., McCarthy, M.L. and Rebok, G.W. (2003) Age, Flight Experience, and Risk of Crash Involvement in a Cohort of Professional Pilots. American Journal of Epidemiology, 157, 874-880. https://doi.org/10.1093/aje/kwg071

[32] Li, G., Baker, S.P., Lamb, M.W., et al. (2002) Human Factors in Aviation Crashes Involving Older Pilots. Aviation, Space, and Environmental Medicine, 73, 134-138.

[33] Agrawal, V., Marinescu, V., Agarwal, M. and McCullough, P.A. (2009) Cardiovascular Implications of Proteinuria: An Indicator of Chronic Kidney Disease. Nature Reviews Cardiology, 6, 301-311. https://doi.org/10.1038/nrcardio.2009.11

[34] Jensen, J.S., Feldt Rasmussen, B., Strandgaard, S., Schroll, M. and BorchJohnsen, K. (2000) Arterial Hypertension, Microalbuminuria, and Risk of Ischemic Heart Disease. Hypertension, 35, 898-903. https://doi.org/10.1161/01.HYP.35.4.898

[35] Rossing, P., Hougaard, P., Borch Johnsen, K. and Parving, H.H. (1996) Predictors of Mortality in Insulin Dependent Diabetes: 10 Year Observational Follow up Study. BMJ, 313, 779-784. https://doi.org/10.1136/bmj.313.7060.779

[36] Bigazzi, R., Bianchi, S., Nenci, R., Baldari, D., Baldari, G. and Campese, V.M. (1995) Increased Thickness of the Carotid Artery in Patients with Essential Hypertension and Microalbuminuria. Journal of Human Hypertension, 9, 827-833.

[37] Wachtell, K., Olsen, M.H., Dahlöf, B., et al. (2002) Microalbuminuria in Hypertensive Patients with Electrocardiographic Left Ventricular Hypertrophy: The LIFE 
Study. Journal of Hypertension, 20, 405-412. https://doi.org/10.1097/00004872-200203000-00015

[38] Mykkänen, L., Zaccaro, D.J., O’Leary, D.H., Howard, G., Robbins, D.C. and Haffner, S.M. (1997) Microalbuminuria and Carotidartery Intima Media Thickness in Nondiabetic and NIDDM Subjects. The Insulin Resistance Atherosclerosis Study (IRAS). Stroke, 28, 1710-1716. https://doi.org/10.1161/01.STR.28.9.1710

[39] Kramer, H., Jacobs, D.R., Bild, D., et al. (2005) Urine Albumin Excretion and Subclinical Cardiovascular Disease. The Multi-Ethnic Study of Atherosclerosis. Hypertension, 46, 38-43. https://doi.org/10.1161/01.HYP.0000171189.48911.18

[40] Upadhyay, A., Hwang, S.J., Mitchell, G.F., et al. (2009) Arterial Stiffness in Mild to Moderate CKD. Journals of the American Society of Nephrology, 20, 2044-2053. https://doi.org/10.1681/ASN.2009010074

[41] Stehouwer, C.D., Gall, M.A., Twisk, J.W., Knudsen, E., Emeis, J.J. and Parving, H.H. (2002) Increased Urinary Albumin Excretion, Endothelial Dysfunction, and Chronic Low Grade Inflammation in Type 2 Diabetes: Progressive, Interrelated, and Independently Associated with Risk of Death. Diabetes, 51, 1157-1165. https://doi.org/10.2337/diabetes.51.4.1157

[42] Barbieri, A., Bursi, F., Mantovani, F., Valenti, C., Quaglia, M., Berti, E., Marino, M, and Modena, M.G. (2011) Prognostic Impact of Left Ventricular Mass Severity According to the Classification Proposed by the American Society of Echocardiography/ European Association of Echocardiography. Journal of the American Society of Echocardiography, 24, 1383-1391. https://doi.org/10.1016/j.echo.2011.08.012

[43] Arnold, J.M., Fitchett, D.H., Howlett, J.G., Lonn, E.M. and Tardif, J.C. (2008) Resting Heart Rate: A Modifiable Prognostic Indicator of Cardiovascular Risk and Outcomes? Canadian Journal of Cardiology, 24, 3A-8A.

[44] Martinez, M.A., Sancho, T., Armada, E., et al. (2003) Prevalence of Left Ventricular Hypertrophy in Patients with Mild Hypertension in Primary Care (Impact of Echocardiography on Cardiovascular Risk Stratification). American Journal of Hypertension, 16, 556-563. https://doi.org/10.1016/S0895-7061(03)00859-8

[45] Okwuosa, T.M., Soliman, E.Z., Lopez, F., Williams, K.A., Alonso, A. and Ferdinand, K.C. (2014) Left Ventricular Hypertrophy and Cardiovascular Disease Risk Prediction and Reclassification in Blacks and Whites: The Atherosclerosis Risk in Communities Study. American Heart Journal, 169, 155-61.e5.

https://doi.org/10.1016/j.ahj.2014.09.013

[46] Tomita, M., Mizuno, S., Yamanaka, H., et al. (2000) Does Hyperuricemia Affect Mortality? A Prospective Cohort Study of Japanese Male Workers. Journal of Epidemiology, 10, 403-409. https://doi.org/10.2188/jea.10.403

[47] Feig, D.I. and Johnson, R.J. (2003) Hyperuricemia in Childhood Primary Hypertension. Hypertension, 42, 247-252. https://doi.org/10.1161/01.HYP.0000085858.66548.59

[48] Kang, D.H., Park, S.K., Lee, I.K. and Johnson, R.J. (2005) Uric Acid-Induced C-Reactive Protein Expression: Implication on Cell Proliferation and Nitric Oxide Production of Human Vascular Cells. Journal of the American Society of Nephrology, 16, 3553-3562. https://doi.org/10.1681/ASN.2005050572

[49] Messerli, F.H., Frohlich, E.D., Dreslinski, G.R., Suarez, D.H. and Aristimuno, G.G. (1980) Serum Uric Acid in Essential Hypertension: An Indicator of Renal Vascular Involvement. Annals of Internal Medicine, 93, 817-821. https://doi.org/10.7326/0003-4819-93-6-817

[50] Culleton, B.F., Larson, M.G., Kannel, W.B. and Levy, D. (1999) Serum Uric Acid 
and Risk for Cardiovascular Disease and Death: The Framingham Heart Study. Annals of Internal Medicine, 131, 7-13.

https://doi.org/10.7326/0003-4819-131-1-199907060-00003

[51] Yu, T.F., Berger, L., Dorph, D.J. and Smith, H. (1979) Renal Function in Gout. V. Factors Influencing the Renal Hemodynamics. The American Journal of Medicine, 67, 766-771.

[52] Tielemans, S.M.A.J., Geleijnse, J.M., Menotti, A., Boshuizen, H.C., Soedamah-Muthu, S.S., Jacobs Jr., D.R., Blackburn, H. and Kromhout, D. (2015) Ten-Year Blood Pressure Trajectories, Cardiovascular Mortality, and Life Years Lost in 2 Extinction Cohorts: The Minnesota Business and Professional Men Study and the Zutphen Study. Journal of the American Heart Association, 4, e001378. https://doi.org/10.1161/JAHA.114.001378

[53] D’Agostino, R.B., Pencina, M.J., Massaro, J.M. and Coady, S. (2013) Framingham Normal cv. Risk Factors with High CVD Risk Estimate. Cardiovascular Disease Risk Assessment: Insights from Framingham. Global Heart, 8, 11-23.

[54] Hlatky, M.A., Greenland, P., Arnett, D.K., et al. (2009) Criteria for Evaluation of Novel Markers of Cardiovascular Risk: A Scientific Statement from the American Heart Association. Circulation, 119, 2408-2416. https://doi.org/10.1161/CIRCULATIONAHA.109.192278

[55] Goff, D.C. Jr., Lloyd-Jones, D.M., Bennett, G., et al. (2013) ACC/AHA Guideline on the Assessment of Cardiovascular Risk: A Report of the American College of Cardiology/American Heart Association Task Force on Practice Guidelines. Circulation, 129, S49-S73. https://doi.org/10.1161/01.cir.0000437741.48606.98

[56] Chatterjee, N., Wheeler, B., Sampson, J., Hartge, P., Chanock, S.J. and Park, J.H. (2013) Projecting the Performance of Risk Prediction Based on Polygenic Analyses of Genome-Wide Association Studies. Nature Genetics, 45, 400-405. 